\title{
Low-Emission Zones in European Countries
}

\author{
M. Tögel*, L. Špička \\ Transport Research Centre, Brno, Czech Republic, \\ *Corresponding author: marek.togel@cdv.cz
}

DOI: 10.2478/trans-2014-0007

\begin{abstract}
Low-emission zones are currently one of several tools which are in use for the improvement of air quality thanks to the limited entry of vehicles to European city centres. This article describes basic characteristics and parameters of low-emission zones in comparison with other types of used restrictions and explains the evaluation system of particularly environmental benefits and impacts. These theoretic assumptions are confronted with established low-emission zones in selected European urban areas; measured benefits and impacts of individual measures are evaluated and compared.
\end{abstract}

KEY WORDS: Low emission zone, LEZ, urban access restrictions, European urban areas, environmental impact.

\section{INTRODUCTION}

One of the most burning issues in urban areas is currently the high air pollution level. Up to a certain extent, this situation is often aggravated by emissions of pollutants (nitrogen dioxide $-\mathrm{NO}_{2}$, aerosols of particulate matter $-\mathrm{PM}_{10}{ }^{1}, \mathrm{PM}_{2.5}{ }^{2}$ ), which are produced as a byproduct of the combustion process of motor vehicle engines $\left(\mathrm{NO}_{2}, \mathrm{PM}_{10}, \mathrm{PM}_{2.5}\right)$ or as a result of the abrasion of movable vehicle parts $\left(\mathrm{PM}_{10}, \mathrm{PM}_{2.5}\right)$. The effects of pollutants have negative effects on population health causing cardiovascular, respiratory, and malignant diseases.

An obvious solution for air pollution is to limit pollutant sources, particularly emissions from road transport. There is a wide range of tools for the reduction of emissions from road transport and their effects can be divided into global and local ones. Global tools include e.g. governmental subsidies for the purchase of electric vehicles or vehicles or buses run on compressed natural gas. In contrast, local tools can be generally called urban access restrictions (ISIS, 2010). Low emission zones are one of the types of the restrictions in use aiming to reduce the amount of emissions of nitrogen dioxide and dust aerosols.

The article is divided into four parts. The first part deals with the general idea of the concept of urban access restrictions and brings the characteristics of basic elements and parameters of one of the types of tools - low-emission zones. The next part describes the system of impacts of low emission zones with particular focus on environmental impacts. This part also contains definitions of measurable characteristics, which are necessary

\footnotetext{
${ }^{1}$ Dust aerosols smaller than $10 \mu \mathrm{m}$.

${ }^{2}$ Dust aerosols smaller than $2.5 \mu \mathrm{m}$.
} 
for the evaluation of effectiveness and operation of low-emission zones. Subsequently, the third part compares these theoretical approaches with the real implemented measures in several European urban areas, and points out differences in approaches to low-emission zones implementation in selected member countries of European Union. The last part of the article identifies drawbacks of low-emission zones.

\section{LOW-EMISSION ZONES}

The term "urban access restrictions" concerns all traffic solutions and restrictions which can be used to improve the environment in urban areas. Regarding typology, there are 2 basic types of traffic restrictions:

1) charging entry to designed zones

2) no entry to designed zones for some types of vehicles

The first approach allows to include all types of vehicles arriving to a designed zone. Regarding the effectiveness, this approach seems more complex and more flexible. The solution complexity is based on the potential effect on all vehicles arriving in a designed zone and in connection to other types of measures (e.g. public transport conception, road traffic management). The flexibility of the tools allows for easier setting of the conditions for entry (charging by vehicle types, charging by daytime, etc.), which allows for better control of the mobility of the arriving vehicles. The drawback of the approach is a demanding preparation to implement such solution, particularly to install the toll gates system and the monitoring system for the evaluation of solution effectiveness (stations for traffic emission measurement, traffic count devices, questionnaire surveys for drivers, etc.).

The second type of the approach allows to limit the entry for undesirable category of vehicles, and this type can be divided into two types of zones (ISIS, 2010). In the case of so-called restriction zones, there is no entry for vehicles whose movement is undesirable for some traffic reason in a given area (traffic flow, safety, protection of transport infrastructure against damage, etc.). The most frequent example is "pushing" heavy vehicles exceeding certain weight out of the city and town centres. In the case of so-called lowemission zones, the arriving drivers are affected based on their share to the air pollution. The criterion for the entry is usually the age of vehicle or emission category. In contrast to the first approach, the second type does not necessarily require the system of toll gates to check the entry. The installation of the monitoring system is as demanding as with the first approach, while the emphasis is generally placed on the monitoring of emissions and analysis of the dynamic composition of vehicle fleet.

The main difference between both types of zones is the purpose of installation with two major goals of the measures:

- reduction of traffic congestions and improved traffic flow

- improvement of the environment through the reduction of emissions from traffic

The purpose of low-emission zones is usually to improve air quality, which is reached by the reduction of emissions from road transport. In contrast, charged entry zones, or so-called traffic restricted zones, usually aim to reduce traffic congestions and improve traffic flow. The purpose of the given types of restriction zones in selected European urban areas is shown in the following graph in Figure 1. 


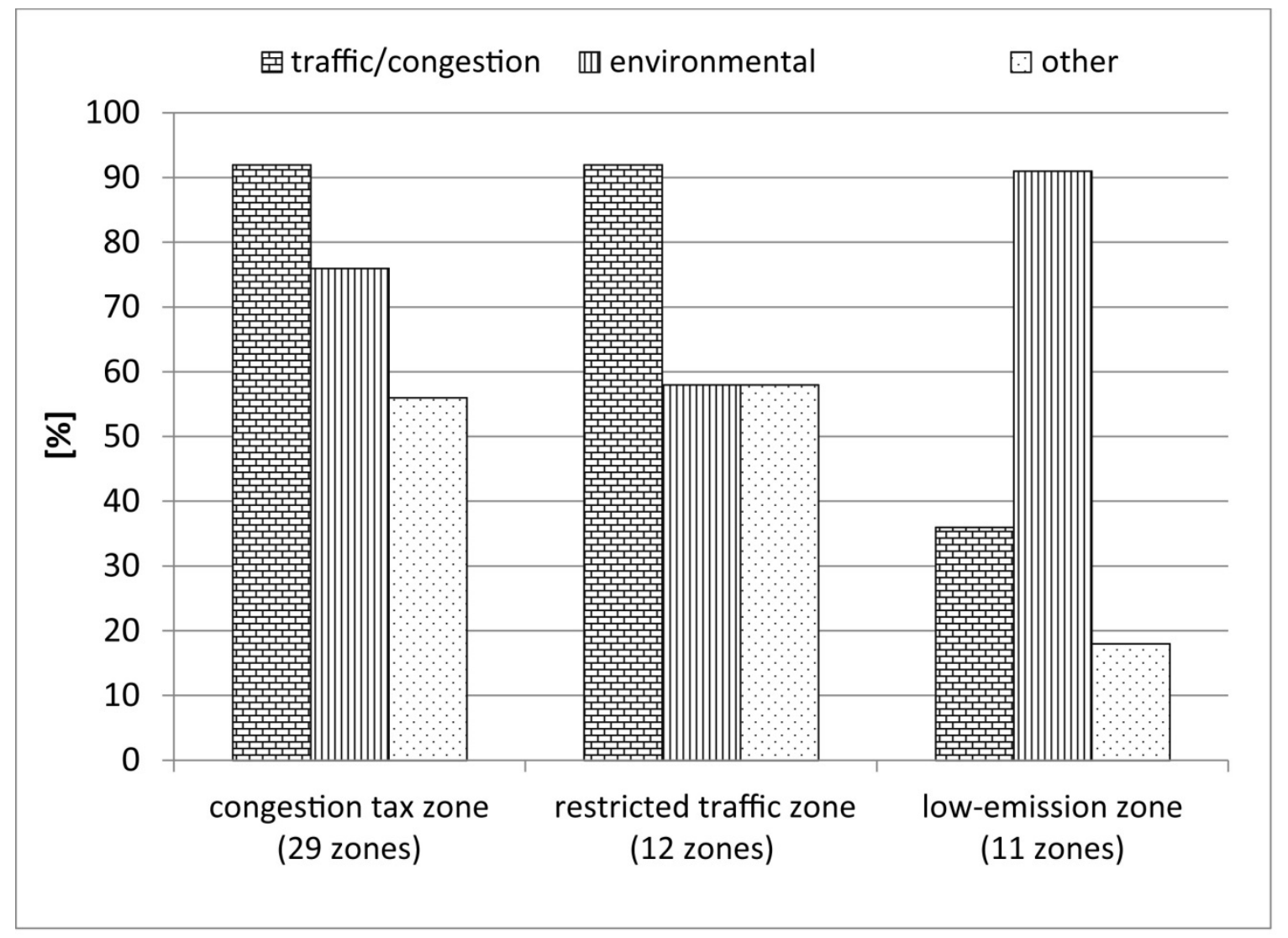

Figure 1: Purpose of introduction of basic types of restricting zones in selected European urban areas (ISIS, 2010).

The low-emission zone (LEZ) can be defined as a geographically delineated area with no entry of vehicles which fail to meet certain requirements. These requirements usually concern emission limits EURO, which are issued within EU directives by the European Parliament and the Council of the European Union. In some member countries, the conditions for entry are replaced with a different characteristic of vehicle technical conditions, e.g. vehicle age. The specific conditions allowing entry of vehicles to LEZ are specified by a country's legislation or a particular LEZ founder, usually a given responsible authority. There are three approaches to set LEZ conditions as follows:

i) conditions are specified by the legislation adopted by the government, and corresponding authorities delineate the geographical area of LEZ

ii) conditions are specified by the legislation adopted by the government, and corresponding authorities delineate the geographical area of LEZ and choose from a wider range of possible conditions specified by the legislation

iii) conditions for entry to LEZ and the geographical scope of LEZ are specified by authorities within the applicable national legislation

The above mentioned three approaches to setting conditions for vehicle entry to LEZ are consequently a cause of different economic, social, and environmental impacts. The first approach is considered the least flexible and the clearest. The second approach is an example of a combination of flexible solutions with the aim to make the given system clearer. The third approach the most considers the needs of municipalities. However, its significant drawback is the incomprehensiveness of such system in the regional and national scale. 
Similarly, the responsibilities of municipalities are determined when issuing exceptions for specific vehicle categories ${ }^{1}$. The designed system may return to municipal authorities the right to grant exceptions, specify vehicle categories which may receive exceptions, or leave these powers fully in the responsibility of municipal authorities.

The Czech legislation gives municipalities the right to introduce a low-emission zone within their jurisdiction in compliance with Act No. 201/2012 Coll., on Air Protection. Municipalities are allowed to introduce a LEZ in case it is located within a special protected area, in a spa town, or in case the corresponding air quality limit values are exceeded within such municipality. Municipal authorities are allowed to grant and exception to all permanent residents within the low-emission zone. Similarly, in cases specified by the legislation, a temporary or permanent individual exception may be granted to specific vehicles ${ }^{2}$ or specific people ${ }^{3}$. Municipal authorities are allowed to specify emission vehicle categories which are allowed to enter LEZs. In addition, municipalities are responsible for the delineation of LEZ area, in order to ensure a detour for transit traffic (Act No. 201/2012 Coll.). The above mentioned situation in the Czech Republic can be classified as the second approach for specifying conditions for LEZs. Based on the research of the situation in selected European countries which introduced LEZs, general basic parameters which need to be specified before the introduction of LEZ are summarized below:

- delineation of LEZ

- $\quad$ types of vehicles for which no entry to LEZ applies

- $\quad$ emission category of vehicles with allowed entry to LEZ

- $\quad$ time applicability of conditions for allowed entry to LEZ

- $\quad$ system of specifying emission categories to specific vehicles

- $\quad$ system of granting exceptions to groups of vehicles or specific vehicle owners

- determination of the validity of conditions to entry to LEZ for vehicle from foreign countries

- $\quad$ determination of sanctions for violating conditions for entry to LEZ

A LEZ founder needs to specify all these parameters either directly on the basis of their responsibilities, or the specification of parameters is given by the legislation. The mentioned parameters allow to create typologically different LEZs which may vary significantly in their efficiency and effectiveness.

\section{SYSTEM OF EVALUATING EFFECTIVENESS OF LOW-EMISSION ZONES}

The monitoring of impacts in relation to the implementation of low-emission zones allows their founder to justify and defend the use of the given tool. The system of effectiveness evaluation of LEZ should reflect the aims and expectations for which a LEZ is introduced. The purpose of LEZs is to improve air quality and consequently to improve the health of population exposed to pollutants. This causal relation (emission reduction $\rightarrow$ air quality improvement $\rightarrow$ population health improvement) needs to be perceived with some

\footnotetext{
${ }^{1}$ e.g. vehicles of integrated rescue system, vehicles transporting impaired people, vehicles of residents inside LEZs, etc.

${ }^{2}$ Vehicles with special equipment, vehicles designed for transport of goods to cultural and special events, and vehicles transporting fuels for hospitals, social institutes, and education facilities.

${ }^{3}$ Ill or impaired people, people whose working hours prevent them from travelling by public transport, and people who would be unable to run their business.
} 
uncertainty. The final goal of the whole measure may by affected by many other external factors, which have effects independently of the implemented measure. The effects of these factors may significantly change the evaluation monitoring measurements, therefore, it is necessary to distinguish the effects by the degree of direct or indirect relations and determine for which effects the effects of external factors need to be taken into account. A study evaluating the benefits and impacts of a LEZ in London (TfL, 2008) also produced a hierarchy of impacts which can be observed as a consequence of a LEZ introduction. The system of LEZ impacts is shown in Figure 2.

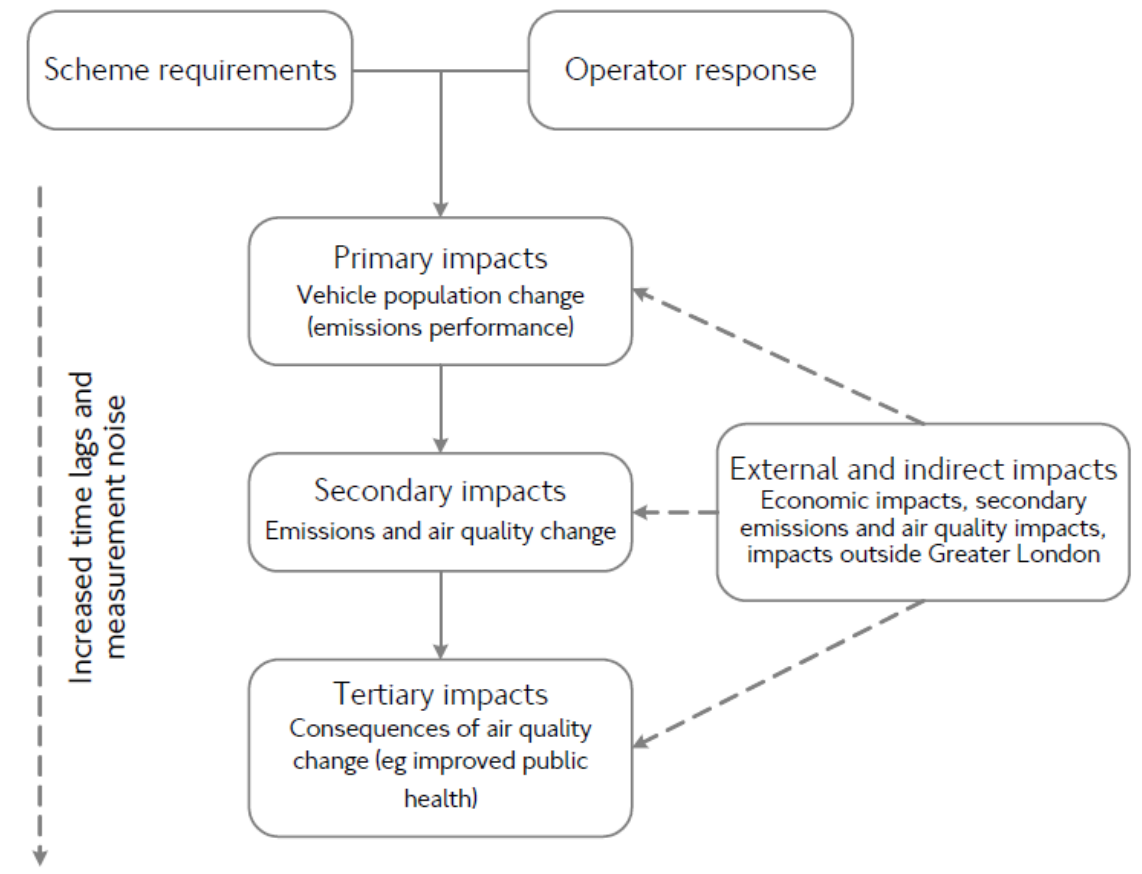

Figure 2: Scheme of impacts as a consequence of LEZ introduction (TfL, 2008).

Impacts can be divided into primary, secondary and tertiary (direct) ones. With the increasing degree of impacts grows the effect of external factors (indirect) and the delayed time in which the given impacts manifest. Since the purpose of LEZ introduction, i.e. air quality improvement and population health improvement, is only reached by secondary and tertiary impacts, it is necessary to set the evaluation system in order to identify the impacts independently and precisely. In general, two basic approaches for identification of impacts are distinguished: modelling and empirical measurement.

The primary impact of LEZ introduction is the change in the dynamic composition of vehicle fleet. The vehicles which are affected by LEZ restrictions will be measured for the share of emission categories within the vehicle fleet. This investigation can be performed through direct empirical measurements with the use of available technologies. Studies from London and Berlin show that these measurements are performed by vehicle count on certain representative transit profiles. The aim of the measurements is to determine the composition of vehicle fleet by emission categories within a given area under conditions without an introduced LEZ and with an introduced LEZ. The difference of these two situations identifies the primary impact of LEZ. The external factor affecting the dynamic composition of the vehicle fleet is the so-called natural renewal of vehicle fleet. This is based on economic conditions in a given municipality, general technological possibilities, and the legislation of a given country. The significance of different external factors may vary. The predictions of external factors are usually based on previous measurements 
of the dynamic composition. Therefore, to evaluate primary impacts correctly, it is necessary to begin the monitoring of the dynamic composition of vehicle fleet several years prior the LEZ introduction. The experience from London and Berlin clearly show that drivers' feedback on LEZ conditions comes before the implementation of LEZ (Tfl, 2008; Lutz \& Rauterberg-Wulff, 2009).

In order to identify secondary impacts, it is necessary to use the results of the primary impacts and take into account the effect of external factors, particularly weather conditions in a given area and emissions from a different source of pollution. The secondary impact is the change in emissions from road transport and change in air quality. The emissions from road transport can only be identified through the emission modelling within a given area with the use of the so-called emission factors ${ }^{1}$ and traffic performance (TfL, 2008). In order to determine traffic performance, it is necessary to measure the dynamic composition of vehicle fleet and traffic volume within a given area. The conversion of the modelled emissions to imissions is performed with the use of the so-called dispersion studies. These studies model the dispersion of emissions of selected pollutants, while the local weather conditions and contributed emissions from other sources of pollution are simulated. This procedure helps to estimate the real impact of the LEZ introduction. The real imissions of NOx and PM10 can be also measured directly through the network of monitoring stations, however, it is impossible to determine precisely the contributed imissions from other sources than road transport and therefore also to determine the impact of the LEZ introduction. Despite this, these measurements are performed in German and British urban areas (Tfl, 2008; Lutz \& Rauterberg-Wulff, 2009).

The identification of tertiary impacts, which includes population health improvement, is the most demanding of all the mentioned ones. The reason is the long delay when the LEZ impacts become obvious on the population health condition and also due to the large amount of external factors which affect the population health condition. There are 3 basic aspects of problematic measurements of tertiary impacts: Firstly, although the clear relation between the harmful effects of pollutants and increasing mortality rate of population is known, the given impacts are very slight in the total mortality rate context. Secondly, there are many parallel processes which influence population health ${ }^{2}$. Thirdly, population health is influenced by lifestyle and the work environment (TfL, 2008).

\section{INTRODUCTION OF LOW-EMISSION ZONES IN WESTERN EUROPEAN COUNTRIES}

Based on the available monitoring reports and evaluation studies, it was possible to evaluate and compare experience with the introduction of LEZs in London, German urban areas, and Swedish urban areas. The procedures for the introduction, parameters and evaluation indicators of LEZs vary for different countries. In general, two basic types of the introduced LEZ systems are distinguished.

\footnotetext{
${ }^{1}$ Emission factors specify the average extent of emissions of a given source for a given substance for a specific type of activity. Emission factors for road transport are usually specified in grams of emissions per a driven kilometre, in grams of emissions per a gram of burnt fuel, or in grams of emissions per a vehicle engine start-up (Hausberger et al., 2009).

${ }^{2}$ Health programmes, anti-smoking policy, etc.
} 


\subsection{Northern system}

In Swedish, Danish, and British urban areas, the LEZs which restrict entry just for heavy vehicles ${ }^{1}$ are introduced. Personal vehicles are not included since their lower contribution to PM10 emissions is assumed in comparison with heavy vehicles. In addition, there is an assumption of faster natural renewal of personal vehicles and therefore higher proportion of emission categories meeting stricter limits. The given system is based on the EURO emission limit classification. The given system uses the information on vehicle emission categories from the national vehicle database. Vehicle emission categories are checked by either a camera system at the entry to the zone, or by random inspection within the LEZ. The restrictions of LEZs are also applicable for foreign vehicles and the restrictions are applicable 24 hours 7 days a week. Since the methodology of monitoring of LEZ impacts varies in different countries, even in time conditions, the effectiveness of the measure cannot be compared between the studied urban areas.

In the Swedish city of Gothenburg, the effectiveness of LEZ introduction between 1996 and 2006 was analysed. Based on the results of the study, it is estimated that the emissions of NOx were reduced by $7.8 \%$ and emissions of PM10 by $33.2 \%$ thanks to the introduction of the LEZ. The highest reduction was reached in the category of vehicles over 16 tonnes. In the case of the city of Gothenburg, the entry to LEZ was allowed to vehicles which had been in the register of vehicles for less than 8 years (Trafikkontoret, 2006).

In February 2008 in London, a LEZ was introduced which restricted entry for vehicles over 12 tonnes, unless they met the EURO 3 emission standard. This was the first stage of the whole project. In July 2008, the second stage was implemented restricting the entry for vehicles from 3.5 to 12 tonnes which failed to meet the EURO 3 emission standard. In October 2010, the third stage was launched. This stage restricts the entry for light commercial vehicles up to 3.5 tonnes and microbuses. The requirements for the emission standard stayed unchanged in this stage. In the final stage 4 (January 2012), the conditions for entry to the LEZ for all so far included vehicles were tightened - all vehicles to enter need to meet the EURO 4 emission standard. A monitoring study published in 2008 evaluated the impacts of the introduction of the LEZ. The dynamic composition of vehicle fleet, which was particularly focused, was identified with the use of a camera system (ANPR ${ }^{2}$ ). The results clearly reflect the response of drivers who were included in the first stage. In March 2007, 58\% vehicles complied with the future conditions, while in December 2007 the proportion of vehicle meeting the conditions of stage 1 reached $70 \%$. The compliance with the conditions for other vehicle categories included in stage 2 stayed virtually unchanged. It is to say that the operators get prepared for the conditions of LEZ only in the last months before the LEZ introduction (TfL, 2008).

The system of effectiveness evaluation of the LEZ in London concerning the reduction of emissions NOx a PM10, is based on three types of components which were monitored in three stages. The first monitoring stage processes information on the so-called natural change in emissions from road transport. The data are obtained from database $\mathrm{LAEI}^{3}$ from 2004 - 2006. The second stage of monitoring is focused on the natural change in emissions from road transport without the effects of LEZ from 2006 - 2007. In order to determine this change, the data from LAEI and data from the national database of vehicle register are compared. The third stage of monitoring estimates the value of the third component, so-called

\footnotetext{
${ }^{1}$ Buses, microbuses, light commercial vehicles, and heavy vehicles.

${ }^{2}$ Automatic Number Plate Recognition.

${ }^{3}$ London Atmospheric Emissions Inventory. A database monitoring emissions from point (e.g. factories), line (e.g. roads), area (e.g. quarries, industrial area), and volume (e.g. air transport) sources since the 1920s (TfL, 2008).
} 
the change in emissions from road transport as a consequence LEZ introduction. The data are obtained from the system ANPR during 2007. The benefits of the LEZ introduction can be estimated through the comparison of all components. The change in emissions as a consequence of the natural renewal of vehicle fleet, which is given by the external factors (economic, technological, etc.) was, on the basis of the first ad second monitoring stages, determined to the value of $-6.9 \%$ for NOx emissions and $-4.8 \%$ for PM10 emissions. The change in emissions as a consequence of LEZ introduction was $-3.2 \%$ for NOx emissions and $-1.8 \%$ for PM10 emissions. Prospectively, the whole change in emissions from road transport in London for 2015 is predicted to reach the values of $-37.6 \%$ for NOx emissions and $-16.8 \%$ for PM10 emissions. The predicted change is not entirely the effect of LEZ introduction, but includes the change in emissions as a consequence of the natural renewal of vehicle fleet (TfL, 2008).

\subsection{German system}

German urban areas have been allowed to introduce LEZs since March 2007. The first LEZs were introduced in 2008, namely in Berlin, Cologne and Hannover. The system of German LEZs differs from the British and Scandinavian ones in stricter conditions, since it restricts entry for all types of double-track vehicles which fail to meet the emission standards. The admissible emission vehicle categories are specified by responsible administrators for each of the LEZs. The system does not check emission vehicle categories through the national vehicle register, but introduces the system of stickers. Every vehicle entering a LEZ is obliged to have a sticker with the applicable emission category on a visible place (Lutz \& Rauterberg-Wulff, 2009).

In Berlin in January 2008, a LEZ was introduced allowing entry of vehicles of emission category 2 and higher ${ }^{1}$. After introducing the LEZ, a change in the dynamic composition of vehicles in comparison to 2007 occurred, particularly in categories of utility and heavy vehicles. The proportion of vehicles of category $1^{2}$ decreased by $29 \%$ for utility vehicles and by $10 \%$ for heavy vehicles. The proportion of vehicles in the highest monitored category (Euro 4 and Euro 5) decreased by 34\% for utility vehicles and by 22\% for heavy vehicles. Regarding personal vehicles, the proportion of the worst emission category 1 decreased by $1.4 \%$ and the proportion of vehicles in the highest emission category (Euro 4 a Euro 5) increased by $6 \%$. The dynamic vehicle composition according to emission standards is usually measured by traffic count on a representative road segment. The modelled impact of LEZ introduction on PM10 a NOx emissions is always related to the modelled situation without LEZ introduction. The benefits of LEZ introduction are not based on vehicle categories, but are related to the whole vehicle fleet. In contrast to 2007, PM10 emissions were reduced by $25 \%$ and NOx emissions were reduced by $15 \%$. For the modelling of emissions from vehicles the emission factors defined in HBEFA methodology, which was produced by Graz University of Technology, Austria, (Lutz \& Rauterberg-Wulff, 2009) are used.

In July 2008 in Munich, a low emission zone was introduced restricting entry for vehicles of category 1 . The Munich study does not analyse the changes in the dynamic composition of vehicles by emission standards, but identifies the proportion of vehicles which fail to meet the determined conditions for entry and which are to be restricted for entry to LEZ. The mentioned information comes from the statistics obtained from the data of the local

\footnotetext{
${ }^{1}$ Vehicle with diesel engines meeting minimum emission limits Euro 2 or Euro 1, if equipped with diesel particulate filter, or vehicles with petrol engines meeting minimum limits Euro 1, equipped with a catalytic converter (Lutz \& Rauterberg-Wulff, 2009).

${ }^{2}$ Vehicles failing to meet emission limits Euro or meeting Euro 1 which are not equipped with a catalytic converter for petrol engines or with diesel particulate filter for diesel engines (Lutz \& Rauterberg-Wulff, 2009).
} 
vehicle register institute. The analysis was performed for the vehicle registered in LEZ, out of LEZ, and for vehicles registered in the whole city of Munich. The percentage of vehicles which fail to meet the conditions for entry to the LEZ does not vary much for all monitored areas. The proportion of personal vehicles which fail to meet the corresponding conditions ranges between 2.8 and $3.6 \%$. The proportion of heavy vehicles which fail to meet the given conditions ranges between 30.5 and 31\%. The expected reduction of PM10 emissions thanks to the LEZ introduction is estimated to approx 17\%. The expected reduction of $\mathrm{NOx}$ emissions was not analysed in detail in the study (BSUGV, 2008).

In Cologne in January 2008, a LEZ was introduced which allowed entry just for vehicles of category 2 and higher. The reduction of emissions from transport in the introduced lowemission zone was predicted on the basis of the measurement of a representative road segment in the city. After the LEZ introduction, the expected reduction of PM10 emissions reached $18 \%$ in the minimum version and $27 \%$ in the maximum version. The reduction of NOx emissions reached $16 \%$ in the minimum version and $27 \%$ in the maximum version. Information on the static or dynamic composition of vehicle fleet was not found (Arentz, 2008).

\section{DRAWBACKS OF THE USE AND EVALUATION OF LOW-EMISSION ZONES}

The first drawback of LEZs as tools for the emission reduction is in their non-complexity. Since the goal of the LEZ introduction is to speed up the process of the natural renewal of vehicle fleet, the given solution system makes pressure on vehicle users just to acquire more environmentally friendly vehicles. The effectiveness of such solution may be relatively beneficial, but otherwise fails to give advantage to vehicle drivers to use any alternative transport modes. While the so-called charged entry zones can be used for transport as well as the environmental goals, the low-emission zones and the traffic restriction zones reach these goals separately. A possible solution is also to use a combination of both types of restrictions like in London or Stockholm, where both types co-exist (TfL, 2008; Hugosson et al., 2006).

The other drawback of low-emission zones is their non-homogeneous methodology of evaluating effectiveness and impacts. This difference is particularly caused by different variations and types which exist in European urban areas. This fact makes the analysis of comparisons of more types of low-emission zones more difficult. The difference between conditions for entry to LEZs in some countries is also rather problematic. For example, since the beginning of LEZ concept introduction German long distance bus operators have criticized the arbitrary specification of the allowed emission categories by the founders of LEZs in German urban areas. The reason that in national scale this competence creates a chaotic map of restrictions and limitations to which the operators find too difficult to adapt (Leonard, 2011).

The most frequent recommendations of experts concerning the given issue are particularly related to long-term planning and awareness, harmonization of basic parameters of LEZ in European countries (particularly a unified vehicle registration by emission categories), and to the unification and determination of evaluating indicator definitions for subsequent comparative studies (Ricci, 2011; ISIS, 2010).

\section{CONCLUSION}

Low-emission zones have recently become one of the most frequently used tools for dealing with the issue of air pollution in the centres of European urban areas. Typologically, LEZs are 
tools included in a wider set of restrictions and limitations called urban access restrictions. Designing LEZs requires to determine 8 basic parameters which may create different types of zones and reflect a purpose or policy of a given city or country. The evaluation of effects and benefits of LEZ is based on the monitoring of primary, secondary and tertiary impacts of LEZ, which are often influenced by external factors. The studies from selected European urban areas which describe LEZ introduction and evaluation of their effectiveness distinguish two types of the used systems so far. The Northern system restricts entry for just heavy vehicles by specific emission categories, while in some countries the system is based on unified conditions for all urban areas and uses the national vehicle database. In contrast, the German system restricts entry for all types of double-track vehicles by certain emission category, provides LEZ founders with competence to determine the admissible emission categories, and uses the system of emission stickers. The general criticism stresses the idea and purpose of LEZ as such, harmonization of approaches when evaluating LEZ effectiveness, and unification of rules and conditions restricting entry to LEZ. The LEZ introduction has experienced a rapid growth after 2000 (ISIS, 2010), however, the methodology for the evaluation of effectiveness and benefits of this tool is only beginning to rise. Deeper preparation of methodology for evaluating particularly the tertiary impacts, which manifest in the long-term run, is expected in the following years. This article deals with the methodology of evaluating particularly primary impact of LEZs, which are used for the initial evaluation of effectiveness of this tool.

\section{ACKNOWLEDGEMENT}

The article was produced under the support of the Ministry of Transport under R\&D project No. CG912-083-190 "Environmental and economical evaluation of clean vehicles promotion".

\section{REFERENCES}

Act No. 201/2012 Coll. On Air Protection. (in Czech)

Arentz, L., 2008. Luftreinhalteplan der Bezirksregierung Köln für das Stadtgebiet Köln [online]. Köln: Bezirksregierung Köln. [cited 2014-09-01]. 115 p. Retrieved from: http://www.polisnetwork.eu/uploads/Modules/PublicDocuments/air-quality-plan_cologneluftreinhalteplan_koeln.pdf

BSUGV, 2008. Luftreinhalte-/Aktionsplan für die Stadt München [online]. München: Bayerishes Staatsministerium für Umwelt, Gesundheit und Verbraucherschutz (BSUGV) [cited 2014-09-01]. Retrieved from: http:/www.regierung.oberbayern.bayern.de/imperia/ md/content/regob/internet/dokumente/bereich5/technischerumweltschutz/lrp/080827_lrp_ muenchen_2te_fortschreibung_gesamt.pdf 
Hausberger, S., Rexeis, M., Zallinger, M., Luz, R., 2009. Emission Factors from the Model PHEM for the HBEFA Version 3 [online]. Graz: Graz Univerzity of Technology [cited 2014-09-01]. 76 p. Retrieved from: http://www.hbefa.net/e/documents/HBEFA_31_Docu_ hot_emissionfactors_PC_LCV_HDV.pdf

Hugosson, M. B., Sjöberg, A., Byström, C., 2006. Facts and Results from the Stockholm Trial - Final version - December 2006 [online]. Stockholm: Miljöavgiftskansliet/Congestion Charge Secretariat [cited 2014-05-22]. 152 p. Retrieved from: http://www.stockholmsforsoket.se/upload/Sammanfattningar/English/Final\%20Report_The \%20Stockholm\%20Trial.pdf

ISIS, 2010. Study on Urban Access Restrictions [online]. Rome: Institute of Studies for the Integration of Systems (ISIS) [cited 2014-05-22]. Retrieved from: http://ec.europa.eu/transport/themes/urban/studies/doc/2010_12_ars_recommendations_to_ the-eu.pdf

Leonard, C., 2011. Low emission zones in Germany: The bus and coach operator's perspective. In Workshop on „Traffic restrictions \& low emissions zones in Europe“, Brussels, March 02, 2011 [online]. Brussels: International Road Transport Union [cited 2014-09-01]. Retrieved from:

http://www.iru.org/cms-filesystem-action?file=Events_2011_bx02march/Leonard.ppt

Lutz, M., Rauterberg-Wulff, A., 2009. Ein Jahr Umweltzone Berlin: Wirkungsuntersuchungen [online]. Berlin: Senatsverwaltung für Gesundheit, Umwelt und Verbraucherschutz [cited 2014-09-01]. 30 p. Retrieved from:

http://www.stadtentwicklung.berlin.de/umwelt/luftqualitaet/umweltzone/download/umwelt zone_1jahr_bericht.pdf

Ricci, A., 2011. Access restriction schemes in European cities: Presentation of the final results of the European Commission study. In Workshop on „Traffic restrictions \& low emissions zones in Europe“, Brussels, March 02, 2011 [online]. Brussels: International Road Transport Union [cited 2014-09-01]. Retrieved from:

http://www.iru.org/cms-filesystem-action?file=Events_2011_bx02march/Ricci.pptx

TfL, 2008. London Low Emission Zone: Impacts Monitoring Baseline Report, July 2008 [online]. London: Transport for London (TfL) [cited 2014-09-01]. 214 p. Retrieved from: https://www.tfl.gov.uk/cdn/static/cms/documents/lez-impacts-monitoring-baseline-report2008-07.pdf 
Trafikkontoret, 2006. Assessment of environmental zone in Göteborg: A report for the Traffic \& Public Transport Authority of the City of Göteborg [online]. Göteborg: Trafikkontoret i Göteborg [cited 2014-09-01]. 24 p. Retrieved from:

http://www2.trafikkontoret.goteborg.se/resourcelibrary/Utv\%C3\%A4rdering\%20MZ\%201

0\%20\%C3\%A5r\%20ENG.pdf

The article was produced under the support of the project

Transport R\&D Centre (CZ.1.05/2.1.00/03.0064) 